\title{
Lymphocytic Neurohypophysitis
}

National Cancer Institute

\section{Source}

National Cancer Institute. Lymphocytic Neurohypophysitis. NCI Thesaurus. Code C121719.

An autoimmune condition affecting the posterior pituitary gland, which is characterized by lymphocytic infiltration, and which often presents as diabetes insipidus. 